\title{
Effect of Drug Abuse and Health Risks Among Undergraduates of Federal Universities in Nigeria
}

\author{
Ofuebe Justina Ifeoma ${ }^{1}$, Adama Grace N. ${ }^{2}$, Nwankwo Benedict Chimezie ${ }^{3}$, Isiaku Wada Bashir ${ }^{4}$, \\ Omeje Grace Ngozi ${ }^{2}$, Agu Fedinand Uzochukwu ${ }^{1} \&$ Nweke Prince Onyemaechi ${ }^{2}$ \\ ${ }^{1}$ Department of Human Kinetics and Health Education, University of Nigeria, Nsukka \\ ${ }^{2}$ Department of Educational Foundations, University of Nigeria, Nsukka \\ ${ }^{3}$ Department of Psychology, Ebonyi State University, Abakaliki, Nigeria \\ ${ }^{4}$ School of General Education, Aminu kano College of Islamic and Legal Studies, Kano State \\ Correspondence: Nweke Prince Onyemaechi, Department of Educational Foundations, Faculty of Education, \\ University of Nigeria, Nsuka - P.M.B. 410101, Enugu State, Nigeria. Tel: 234-(0)-806-445-1455. E-mail: \\ nweke.prince@unn.edu.ng
}

Received: February 19, 2020 Accepted: May 6, 2020 Online Published: June 10, 2020

doi:10.5539/gjhs.v12n8p107 URL: https://doi.org/10.5539/gjhs.v12n8p107

\begin{abstract}
Objective: The study investigated the effect of drug abuse and health risks among undergraduates of Federal Universities in Nigerian.

Methods: The study adopted a descriptive research design. The sample of the study consisted of four hundred and fifty-eight (458) undergraduates. The study adopted structured questionnaire. Cronbach Alpha Reliability Co-efficient was used to determine the instruments which yielded reliability coefficients of 0.78 . Data collected were analyzed using mean and standard deviation. The questionnaire items were drawn and coded on a 4-point scale: Strongly Agree -4 points, Agree -3 points, Disagree -2 points, and Strongly Disagree -1 point. These responses were based on positively worded items while reverse was for the negatively worded items. The average score from coded data $(4+3+2+1=10 / 4)$ was 2.50 .
\end{abstract}

Results: The findings of the study indicated that health risks of drug abuse can leads to drug addiction, hepatitis, HIV/AIDs, cancer or mental illness, heart or lung disease, heart attack, communicable diseases, brain damages, mental confusion, depression and suicidal thoughts or attempt to commit suicide. The findings also revealed that risks factors of drugs abuse among undergraduates includes influence of peer pressure, lack of basic knowledge about the dangers of drugs, lack of parental supervision, poor relationship with parents and poor achievement in school.

Conclusion: In view of the above findings, it is concluded that there should be an intense media campaign aimed at enlightening the undergraduates and indeed Nigerians at large on the dangers and consequences of drug abuse and the health risks.

Keywords: drug, drug abuse, risks factors, health risks, undergraduates

\section{Introduction}

As Nigeria witnesses a rapid speed of urbanization, some Nigerian undergraduates are unable to adjust to their changing environment. Consequently, such students become victims of a disordered life and this might lead to drug abuse. Such abusers become of great concern to the family and society at large. During the oil boom days in Nigeria (from the beginning of 1970s to the dawn of the 80s), nobody thought of an alternative business idea, but eventually when the oil economy collapsed, it brought with it trial of retrenchment instead of employment in the public and private sectors. The problem of readjustment was one that could not immediately be solved. So, alternative means of maintaining the status quo were therefore sought since there were no longer jobs. Hence, they became the favourite couriers of the drug barons prior to the late eighties. The use and abuse of drugs that have the capacity to alter moods, behaviour and thought (i.e. psychoactive drugs) were considered uncommon in Nigeria. The society's initial resentment was against cannabis (Indian-Hemp) use, because of the psychological, social and physical effect (Paddock, 2018). In response to the popular outcry against the danger, the Federal Government 
responded by promulgating India hemp decree of 1966 to control it cultivation, distribution, sale and use.

However, the Decree was amended in 1975 and 1984. In between this period, research evidence show by National Drug and Alcohol Research Centre (NDARC) that licit drugs were also commonly abused (NDARC, 2017). Among the legal drugs abused were alcoholic beverages, central nervous system stimulant, sleep-inducing drugs such as barbiturate and the benzodiazepines such like (valium, laxotan, activan, etc. (NDARC, 2017). Up till the end of the seventies, the uses of narcotic drugs (Pethiodine, Heroin, Morphine, etc.) that essentially relieve pain and create euphona were used for medical and scientific purpose only. They were kept in hard drug cupboards of hospitals to ensure adequate monitoring. The abuse of narcotic drug was then a phenomenon of health care works only. Not until arrest of a narcotic drug trafficker made at the Murtala Mohammed International Airport, Lagos in 1984, title or no attention was paid to abuse of narcotic drugs (NDARC, 2017).

The spate of arrest of Nigerians in Europe, South-East Asian and North America for illicit drugs resulted in the enactment of miscellaneous offences (special military tribunal and Indian hemp, Amendment) Decree Nos 20 and 27 of 1984 respectively. This legislation introduced new measures to minimize the incidence of drug abuse and trafficking. In 1986, by the amendment of the decree, the death penalty prescribed by the miscellaneous decree was replaced with various prison forms of up to imprisonment (Kelly, 2008). Within the last decree was replaced with various prison forms of up to imprisonment. Within the last decade, consumption of hard drugs has risen drastically in Nigeria; heroin and cocaine are now abused along with the traditional drugs such as alcohol, cannabis, amphetamines and other dependence producing drugs. Students between the ages 16 to 24 years constitute the high risk-groups, with females getting more involved than the use to be (Kelly, 2008). Other groups of abusers are the so called young executive, prostitutes, drivers, conductors, graduate, civil servant artistes (National Institute of Drug Abuse, 2014).

A drug can be defined as a substance that may perhaps, bring about an adjustment in the organic or biological function through its chemical measures. According to Fawa (2003), drug is defined as any substance, which is used for treatment or prevention of a disease in man and animals. Drug according to Fareo (2012), alters the body functions either positively or otherwise depending on the body composition of the user, the type of drug used, the amount used and whether used singly or with other drugs at the same time. Drugs according to Alewu and Nosiri (2014) are broadly classified into two, namely: legal or licit and illegal or illicit. The legality of the use drugs for non-medical purpose is of two types: hard use drugs and soft use drugs. The hard use drugs are those that seriously disable the individual as function member of the society be severe emotional and physical dependence e.g. Hersin, morphine, colane, Indian hemp and their analogues. The drug use in the hard sense is central to the user's life that the user cannot do without. Soft-use drugs are less depence, maybe emotional dependence but little or no physical dependence, except with health (alcohol, barbitrolate) e.g. sedative, tranquilizers amphetamines, hallucinogen and tobacco. Drug used in the soft sense is merely incidental. However, a soft-use drug can be continuous to achieve a hard use. The precise dangers and effect of drug abuse in our society among the students have been a largest of research and review by Alewu and Nosiri (2014) for some time. A drug refers to a substance that could bring about a change in the biological function through its chemical actions (Okoye, 2001). It is also considered as a substance that modifies perceptions, cognition, mood, behaviour and general body functions (Balogun, 2006). They could thus, be considered as chemical modifiers of the living tissues that could bring about physiological and behavioural changes (Nnachi, 2007).

Drug abuse can be defined as the process by which drugs are misuse in way that is harmful to individual or persons. It is a form of substance-related disorder which is also known as substance abuse. According to World Health Organization (WHO, 2011), drug abuse refers to the harmful or hazardous use of psychoactive substances, including alcohol and illicit drugs. Drugs are most often associated with alcohol, amphetamines, cannabis and cocaine (McCabe, Boyd, \& Teter, 2009). In similar study carried out by Oshikoya and Alli (2006), drug abuse was defined as a non-medical self administration of a substance to produce psychoactive effects, intoxication or altered body image, despite the knowledge of its potential adverse effects. Drug abuse in the context of this study, can be defined as the chance to misuse a particular drug without a former medical directive from qualified health practitioners. It can also be viewed as the unlawful overdose in the use of drugs (Fareo, 2012).

There is a lot of contradiction even among specialists on how medications ought to be arranged. This implies a similar medication may be sorted distinctively under two unique frameworks. Along these lines, it's basically difficult to make a lot of defining drug characterization principles. However, here are some of the most common as cited by Kindra and Brian (2019):

i. Opioids: These are derived from the drug opium or synthetic versions that mimic the chemical structure of opium. This class of drugs interacts with neurotransmitters in the brain to block signals. They cause 
both intense feelings of pleasure and can block pain.

ii. Alcohol: This is one of the most widely abused substances across the world. It's legal to consume alcohol in Nigeria, though alcohol is a central nervous system (CNS) depressant. It causes severe long-term damage to the liver.

iii. Cocaine: These drugs accelerate the activity of the CNS making a person feel energized, focused, and alert for long periods of time. The converse reaction is that a person feels edgy, paranoid and angry.

iv. Inhalants: Mostly consumed through breathing, these drugs can exist in vapor form at room temperature. Most inhalants are found in household items often used by adolescents. They tend to be less addictive than other substances but are incredibly dangerous to human heart.

v. Hallucinogens: By interacting with the CNS, this class of drugs might cause a user to hear things or imagine situations that don't exist.

vi. Cannabis: This is one of the most widely used drugs across the world. Cannabis affects the cannabinoid receptors in the brain. This drug comes in many different forms and affects each user differently.

vii. New psychoactive substance: This refers to anything that is been laboratory created to mimic naturally occurring drugs falls into this category. This includes synthetic cannabis, lab-created ketamine, and more.

In a studied carry out by Michael (2019), the aim of drug classification is to ensure that users make use of drugs safely to achieve the utmost benefit. Ultimately, every time user takes a particular drug, the use observes that the body chemistry is altered. While this effect is meant to be therapeutic, it can also cause side effects that may be harmful. For instance, when user takes multiple drugs, the body chemistry may change in such a way that a drug is far less effective or the side effects are far more severe. The author further cited that, a drug classification is a term used to describe medications that are grouped together because of their similarity, which the authors mentioned four dominant methods of classifying these groups, such as: by their therapeutic use, meaning the types of condition they are used to treat; by their mechanism of action, meaning the specific biochemical reaction that occurs when taking a drug; by their mode of action, meaning the specific way in which the body responds to a drug; and by their chemical structure.

The reasons for the abusive of substances may vary from person to another according to individual understanding. In a study carried out by Kamlesh and Soma (2012), the causes of drug or substance abuse are classified into three categories and they include: social factors, which has to do with: influence peer pressure (one of the most important causes), role-Modeling, easy availability, conflicts, cultural reasons, lack of social support and social attitude. Psychological factors according to Vivek and Tharu (2011), include social rebelliousness (disobedience), early initiation, poor control, low self-esteem, poor stress management, childhood loss or trauma and psychological distress. And biological factors include family history, genetic predisposition, personality disorder, or a medical disorder, reinforcing effects of drugs and withdrawal effects and craving. Additional risk factors contributing to the causes of drug abuse include: unstable home environment, often due to drug abuse or mental illness of the parent, a poor relationship with parents, use of drugs by friends/peers, permissive attitude towards their own drug use and the drug use of the adolescent, behavioural problems combined with poor parenting, poor achievement in school, approval of drug use in the school, peer group or community and availability of drugs from friends (Natasha, 2019).

Other health risks causes by drug abuse among undergraduates as posited by National Institute of Drug Abuse (2017) include a wide range of short-term and long-term, direct and indirect effects. These effects often depend on the specific drug or drugs used, how they are taken, how much is taken, the person's health, and other factors that may be contributed to such effect. According to the institute, short-term effects can range from changes in appetite, wakefulness, heart rate, blood pressure, mood to heart attack, stroke, psychosis, overdose, and even death. These health effects may occur after just one use. On the other hand, longer-term effects can include heart or lung sickness, malignant growth, psychological sickness, HIV/AIDS, hepatitis, and others. Long-term drug use can likewise prompt dependence. Illicit drug use is a mind issue. Not every person who uses medications will get dependent, yet for a few, tranquilize use can change how certain mind circuit functions. These mind changes meddle with how individuals experience ordinary delights in life, for example, nourishment and sex, their capacity to control their feeling of anxiety, their dynamic, their capacity to learn and recall, and so forth. These progressions make it significantly harder for somebody to quit taking the drug in any event, when it is having negative effect on their life and they need to stop. Additionally, drug uses have indirect effect on both the individuals who are ingesting drugs or on people around them. This can incorporate influencing an individual's nourishment; rest; decision making and impulsivity; and hazard for injury, viciousness, injury, and transmittable diseases. Drug use 
can also affect babies born to women who use drugs while pregnant. Broader negative outcomes may be seen in education level, employment, housing, relationships, and criminal justice involvement (National Institute of Drug Abuse, 2017).

Furthermore, Gateway (2015) in their studies revealed the effects of drug abuse on health. According Gateway, substance use disorders are associated with a wide range of short and long-term health effects. They can vary depending on the type of drug, how much and how often it's taken and the person's general health. Overall, the effects of drug abuse and dependence can be far-reaching. They can impact almost every organ in the human body. In further study, the posited that side effects of drug addiction may include a weakened immune system, increase in risk of illness and infection. Also, heart conditions ranging from abnormal heart rates to heart attacks and collapsed veins as well as blood vessel infections from injected drugs; nausea and abdominal pain, which can also lead to changes in appetite and weight loss; increased strain on the liver, which puts the person at risk of significant liver damage or liver failure; seizures, stroke, mental confusion and brain damage; lung disease; problems with memory, attention and decision-making, which make daily living more difficult and global effects of drugs on the body, such as breast development in men and increases in body temperature, which can lead to other health problems. Other risk factors associated with drug abuse as highlighted by Kamlesh and Soma (2012), and they include:

Academics: Declining grades, absenteeism from school/college and other activities, and increased potential for dropping out of school/college are problems associated with youth substance abuse. Hawkins, Catalano, and Miller (2002) were of the opinion that, a low level of commitment to education and higher truancy rates appear to be related to substance use among youth. Cognitive and behavioral problems experienced by alcohol and drug using youth may interfere with their academic performance and also present obstacles to learning for their classmates (Hawkins, Catalano \& Miller, 2002).

Health and Safety: Psychoactive drugs affect the central nervous system and act by altering a person's feelings, thoughts and behaviour. They act by directly affecting the brain or the central nervous system (CNS) leading to various complication and health and behavioural problems. Injuries due to accidents (such as car accidents), physical disabilities and diseases, and the effects of possible overdoses are among the health-related consequences of youth substance abuse.

Mental health: Mental health problems such as depression, developmental lags, apathy, withdrawal, and other psychosocial dysfunctions frequently are linked to substance abuse among adolescents. Substance-abusing youth are at higher risk than nonusers for mental health problems, including depression; conduct problems, personality disorders, suicidal thoughts, attempted suicide, and suicide. Suicide is the second leading cause of death among college students (James, 2010).

Peer Groups: Substance-abusing youth often are alienated from and stigmatized by their peers. Adolescents using alcohol and other drugs also often disengage from school and community activities, depriving their peers and communities of the positive contributions they might otherwise have made.

Families: In addition to personal adversities, the abuse of alcohol and other drugs by youth may result in family crises and jeopardize many aspects of family life, sometimes resulting in family dysfunction. Both siblings and parents are profoundly affected by alcohol- and drug-involved youth

Work place: In terms of work, many substance users had missed going to work, frequently borrowed money from colleagues and friends, had shown poor productivity and faced a lack of respect from employers and colleagues. Many of them were warned by their employers about their hazardous drinking practices, which also resulted in frequent arguments and quarrels with their employers and colleagues, thereby demeaning the individual (Kamlesh \& Soma, 2012).

Drug problem is a worldwide phenomenon despite intensive efforts directed towards controlling it, the problem seems intractable. Nigeria and other African countries have in the past adopted measures aimed at controlling drug abuse such as: promulgation of laws that expanded for feature of assets by drug abusers; pretrial detention of persons accused of serious drug abuse; severe trail and sentence penalties against drug offenses and offenders; mandatory prison sentences for large scale distributors of marijuana; establishment of drug law enforcement agency monitors drug abuse and persecute offenders; creating of drug law enforcement grant programme to assist state and local efforts in drug and abuse control; treatment and rehabilitation of drug addicts; increased educational programmes and medical sensitization aimed at enlightening the people on the danger of drug abuse; and expansion of drug law enforcement assistance in rural areas. Research by Kosterman, Hawkins, Haggerty, Spoth and Redmond (2001) further posited other strategies for the prevention of drug abuse among students, such as family-based prevention programme that has to do with parental monitoring and supervision critically designed for 
drug abuse prevention. These skills can be enhanced with training on rule-setting, techniques for monitoring activities, praise for appropriate behaviour, and moderate, consistent discipline that enforces defined family rules (Kosterman, Hawkins, Haggerty, Spoth, \& Redmond, 2001). Drug education and information for parents or caregivers reinforces is another measure for prevention of drug abuse among students, and this measure enable the parents to educate their children about the harmful effects of drugs and opens opportunities for family discussions about the abuse of legal and illegal substances (Bauman, Foshee, Ennett, Pemberton, Hicks, King, \& Koch, 2001). Another measure as posited by Spoth, Redmond, Trudeau, and Shin (2002b) is family-focused interventions for the general population which can positively change specific parenting behavior that can reduce later risks of drug abuse of the child. Webster-Stratton, Reid, and Hammond (2001) further posited that, the institutions of higher learning are also responsible for the fight against drug abuse among the undergraduates through prevention programmes designed to intervene as early as pre-school of the child to address risk factors for drug abuse, such as aggressive behavior, poor social skills, and academic difficulties.

However, several broad prevention strategies can be applied to most substance use issues. The Substance Abuse and Mental Health Services Administration (2017) has identified six strategies that can help shape prevention plans and they include: information dissemination increases knowledge and changes attitudes through communications. This method of learning is mainly one-way, such as classroom speakers or media campaigns; Prevention education is a two-way approach to teaching participants important social skills. These skills can include resisting pressure to use drugs, looking at the intent behind advertising, or developing other skills used in making healthy choices; Positive alternatives provide fun, challenging, and structured activities with supervision so people have constructive and healthy ways to enjoy free time and learn skills. These alcohol- and drug-free activities help people particularly young people stay away from situations that encourage use of alcohol, tobacco, or illegal drugs; Environmental strategies are aimed at the settings and conditions in which people live, work, and socialize. These strategies call for change in policies to reduce risk factors and increase protective factors, for example, tighter zoning restrictions on alcohol outlets or stronger enforcement to prevent underage purchases of alcohol and tobacco products. As these changes are carried out at the community level, they can have a sweeping impact. Community-based processes strengthen resources such as community coalitions to prevent substance use and misuse. Organizing, planning, and networking are included in this strategy to increase the community's ability to deliver effective prevention and treatment services. Identification of problems and referral to services are crucial to the prevention of substance use. This process includes determining when the behavior of people who are at high risk or who are using alcohol, tobacco, and other drugs requires education or other intensive interventions (National Institute of Drug Abuse, 2003).

\section{Objectives of the Study}

The general objective of this study is to determine the effect of drug abuse and health risks among undergraduates of Federal Universities in Nigerian. Specifically, the study sought to:

1. Fine out the risks factors of drug abuse among undergraduates of Federal Universities in Nigerian?

2. Ascertain the health risks of drug abuse among undergraduates of Federal Universities in Nigerian?

3. Examine the strategies to prevent drug abuse among undergraduates of Federal Universities in Nigerian?

\section{Research Questions}

The study was guided by the following research questions.

1. What are the risks factors of drug abuse among undergraduates of Federal Universities in Nigerian?

2. What are the health risks/consequences of drug abuse among undergraduates of Federal Universities in Nigerian?

3. What are the strategies to prevent drug abuse among undergraduates of Federal Universities in Nigerian?

\section{Research Method}

A descriptive research design was used for this study. The study was carried out in the six (6) selected federal universities in Nigerian (Nnamdi Azikiwe University, Awka; Federal University, Ndifu-Alike, Ebonyi State; Michael Okpara University of Agricultural Umudike; Federal University of Technology, Owerri; and University of Nigeria, Nsukka). The population for this study comprised 458 respondents, which was made up of 250 academics staff and 208 non-academics staff. Since the population is manageable, it was used as the sample size. The study adopted simple random sampling technique. The instrument for data collection was structured questionnaire developed by the researchers. The instrument was face validated by three experts; one from the Department of Human Kinetics and Health Education; one from Department of Psychology; and one from Department of 
Educational Foundations, all from the University of Nigeria, Nsukka. The experts were to find out if the instrument would measure what it intended to measure. They were requested to examine the instrument to ensure that it would help the researchers collect pertinent data for answering the research questions and testing the null hypotheses. Cronbach Alpha Reliability Co-efficient was used to determine the reliability of the instrument, which yielded index of 0.78. The questionnaire items were drawn and coded on a 4-point scale as follows: Strongly Agree (SA) 4, Agree (A) 3, and Disagree (D) 2, Strongly Disagree (SD) 1 point. The average score from the coded data $4+3+2+1$ $=10 / 4$ was 2.50 . This was taken as cut-off point for answering the research question. The experts examined the instrument in terms of clarity, suitability and relevance. Mean and standard deviation was used to answer all the research questions.

\section{Results}

5.1 Research Question One: What Are the Risks Factors of Drug Abuse Among Undergraduates in Nigerian Federal Universities?

Table 1. Mean ratings and standard deviation of respondents on the risks factors of drug abuse among undergraduates in Nigerian Federal Universities

\begin{tabular}{lllll}
\hline S/N & Risks Factors of Drug Abuse & Mean $(\mathbf{x})$ & SD & Decision \\
\hline 1 & Influence of peer pressure & 3.04 & 0.33 & $\mathrm{~A}$ \\
2 & Lack of social support and social attitude & 3.55 & 0.30 & $\mathrm{~A}$ \\
3 & Lack of basic knowledge about the dangers of drugs & 2.98 & 0.33 & $\mathrm{~A}$ \\
4 & Lack of parental supervision & 2.76 & 0.34 & $\mathrm{~A}$ \\
5 & Cultural reasons & 2.88 & 0.33 & $\mathrm{~A}$ \\
6 & Lack of social support and social attitude & 3.23 & 0.32 & $\mathrm{~A}$ \\
7 & Disobedience & 3.55 & 0.30 & $\mathrm{~A}$ \\
8 & Poor control and low self-esteem & 3.07 & 0.32 & $\mathrm{~A}$ \\
9 & Psychological distress & 3.12 & 0.32 & $\mathrm{~A}$ \\
10 & Biological factors & 2.99 & 0.33 & $\mathrm{~A}$ \\
11 & Unstable home environment & 2.88 & 0.33 & $\mathrm{~A}$ \\
12 & poor relationship with parents & 2.99 & 0.33 & $\mathrm{~A}$ \\
13 & Use of drugs by friends/peers & 2.95 & 0.33 & $\mathrm{~A}$ \\
14 & Poor achievement in school & 2.78 & 0.34 & $\mathrm{~A}$ \\
15 & absenteeism from school/college and other activities & 3.08 & 0.32 & $\mathrm{~A}$ \\
\hline & Cluster Mean & $\mathbf{3 . 0 6}$ & $\mathbf{0 . 3 2}$ & $\mathrm{A}$ \\
\hline
\end{tabular}

The results in Table 1 revealed the mean ratings and standard deviation of respondents on the risks factors of drug abuse among undergraduates in Nigerian Federal Universities. The results showed that the respondents accepted that the above items are causes or risks factors of drug abuse among undergraduates with mean score ranged from $2.76(0.34 \%)$ to $3.55(0.30 \%)$. While the cluster means score was 3.06 with a standard deviation of 0.32 . Therefore, the risks factors of drug abuse among undergraduates in Nigeria Federal Universities include: influence of peer pressure, lack of social support and social attitude, lack of basic knowledge about the dangers of drugs, lack of parental supervision, cultural reasons, lack of social support and social attitude, disobedience, poor control and low self-esteem, psychological distress, biological factors, unstable home environment, poor relationship with parents, use of drugs by friends/peers, poor achievement in school and absenteeism from school/college and other activities. Therefore, this implied that the respondents were homogenous in their responses. 
5.2 Research Question Two: What Are the Health Risks of Drug Abuse Among Undergraduates in Nigerian Federal Universities?

Table 2. Mean ratings and standard deviation of respondents on health risks of drug abuse among undergraduates in Nigerian Federal Universities?

\begin{tabular}{lllll}
\hline S/N & Health Risks of Drug Abuse & X & SD & Decision \\
\hline 16 & Drug addiction (Brain disorder) & 2.45 & 0.35 & A \\
17 & Hepatitis & 3.03 & 0.33 & A \\
18 & HIV/AIDS & 2.25 & 0.36 & A \\
19 & Cancer or mental illness & 2.55 & 0.35 & A \\
20 & Heart or lung disease & 3.09 & 0.32 & A \\
21 & It leads to death & 3.55 & 0.30 & A \\
22 & Mood to heart attack & 2.99 & 0.28 & A \\
23 & Blood pressure & 3.35 & 0.31 & A \\
24 & It affects personal decision making & 3.56 & 0.30 & A \\
25 & Risk for trauma & 2.67 & 0.34 & A \\
26 & Violence & 2.90 & 0.33 & A \\
27 & Communicable diseases & 3.45 & 0.31 & A \\
28 & It increase the risk of illness and infection & 2.81 & 0.34 & A \\
29 & Brain damages & 2.74 & 0.34 & A \\
30 & mental confusion and brain damage & 3.05 & 0.33 & A \\
31 & It affect the central nervous system & 3.25 & 0.32 & A \\
32 & Depression & 3.28 & 0.31 & A \\
33 & Suicidal thoughts or attempt to commit suicide & 3.27 & 0.31 & A \\
\hline & Cluster Mean & $\mathbf{3 . 0 1}$ & $\mathbf{0 . 3 2}$ & A \\
\hline
\end{tabular}

Result in Table 2 revealed the mean values ranged from $2.25(0.36 \%)$ to $3.56(0.30 \%)$. These values were up to 2.50 mean bench mark for decision making. This therefore, implies that the respondents agreed that all the items were health risks of drug abuse among undergraduates in Nigerian Universities. While the cluster means score was 3.01 with the standard deviation of 0.32 ; indicating that the respondents were homogenous in their responses. Therefore, the health risks of drug abuse among undergraduates in Nigeria Federal Universities include: drug addiction (Brain disorder), hepatitis, HIV/AIDS, cancer or mental illness, heart or lung disease, mood to heart attack, blood pressure, it affects personal decision making, risk for trauma, violence, communicable diseases, it increase the risk of illness and infection, brain damages, mental confusion and brain damage, depression and suicidal thoughts or attempt to commit suicide. 


\subsection{Research Question Three: What Are the Strategies to Prevent Drug Abuse Among Undergraduates in Nigerian} Federal Universities?

Table 3. Mean ratings and standard deviation of respondents on the strategies to prevent drug abuse among undergraduates in Nigerian Federal Universities

\begin{tabular}{|c|c|c|c|c|}
\hline $\mathbf{S} / \mathbf{N}$ & Strategies To Prevent Drug Abuse & $\mathbf{X}$ & SD & Decision \\
\hline 34 & Promulgation of laws that expanded for feature of assets by drug abusers & 3.21 & 0.32 & A \\
\hline 35 & Pretrial detention of persons accused of serious drug abuse & 3.02 & 0.33 & A \\
\hline 36 & Mandatory prison sentences for large scale distributors of marijuana & 2.99 & 0.33 & A \\
\hline 37 & Establishment of drug law enforcement agency monitors drug abuse and persecute offenders & 2.95 & 0.33 & A \\
\hline 38 & $\begin{array}{l}\text { Creating of drug law enforcement grant programme to assist state and local efforts in drug } \\
\text { and abuse control }\end{array}$ & 2.96 & 0.33 & A \\
\hline 39 & Restrictions on smoking locations & 3.20 & 0.32 & A \\
\hline 40 & Medical sensitization aimed at enlightening the people on the danger of drug abuse & 3.20 & 0.32 & A \\
\hline \multirow[t]{2}{*}{41} & Parental monitoring and supervision critical designed for drug abuse prevention & 3.21 & 0.32 & A \\
\hline & Cluster Mean & 3.09 & 0.32 & $\mathbf{A}$ \\
\hline
\end{tabular}

Result in Table 3 revealed that items 31-38 had their mean values ranged from $2.95(0.33 \%)$ to $3.21(0.32 \%)$. These values were up to 2.50 mean bench mark for decision making. This therefore, implies that the respondents agreed that all the items were the strategies to prevent drug abuse among undergraduates in Nigerian Federal Universities. While the cluster mean of 3.09, with the standard deviation of 0.32 . The result in Table 3 also revealed that the standard deviation of the 31 - 38 items ranged from $0.64-0.80$; indicating that the respondents were homogenous in their responses. Therefore, the strategies to prevent drug abuse among undergraduates in Nigeria Federal Universities include: promulgation of laws that expanded for feature of assets by drug abusers, pretrial detention of persons accused of serious drug abuse, mandatory prison sentences for large scale distributors of marijuana, establishment of drug law enforcement agency monitors drug abuse and persecute offenders, creating of drug law enforcement grant programme to assist state and local efforts in drug and abuse control, restrictions on smoking locations, medical sensitization aimed at enlightening the people on the danger of drug abuse and parental monitoring and supervision critical designed for drug abuse prevention

\section{Discussion}

The findings of the study revealed that risks factors of drugs abuse among undergraduates includes influence of peer pressure, lack of social support and social attitude, lack of basic knowledge about the dangers of drugs, lack of parental supervision, poor control and low self-esteem, unstable home environment, poor relationship with parents and poor achievement in school. These factors can be known as cause of drug abuse. This finding is in agreement with the findings of Kamlesh and Soma (2012) who noted that the causes of drug or substance abuse as social factors, which has to do with: influence peer pressure (one of the most important causes), role-Modeling, easy availability, conflicts, cultural reasons, lack of social support and social attitude. The finding is also in line with the findings of Vivek and Tharu (2011) who posited psychological factors as one of the causes of drug abuse among undergraduates which include social rebelliousness (disobedience), early initiation, poor control, low self-esteem, poor stress management, childhood loss or trauma; and biological factors, such as family history, personality disorder and reinforcing effects of drugs.

The findings of the study indicate that health risks of drug abuse can leads to drug addiction, hepatitis, HIV/AIDS, cancer or mental illness, Heart or lung disease, heart attack, communicable diseases, brain damages, mental confusion, depression and suicidal thoughts or attempt to commit suicide. This finding is in agreement with National Institute of Drug Abuse (2017) who observed that drug abuse can have a wide range of short-term and long-term, direct and indirect health effects. According to the institute, short-term effects can range from changes in appetite, wakefulness, heart rate, blood pressure, and/or mood to heart attack, stroke, psychosis, overdose, and even death. The long term health effects include heart or lung disease, cancer, mental illness, HIV/AIDS, hepatitis, and others.

The findings of the study also indicated strategies to prevent drug abuse among undergraduates in Nigerian Federal 
Universities. The finding agreed with Research by Kosterman, Hawkins, Haggerty, Spoth \& Redmond (2001) who asserted that strategies for the prevention of drug abuse among students can achieved through family-based prevention programme that has to do with parental monitoring and supervision critical designed for drug abuse prevention. The finding is also in agreement with Spoth, Redmond, Trudeau, and Shin (2002b) who posited measure to prevent drug abuse among students, which include family-focused interventions for the general population which can positively change specific parenting behavior that can reduce later risks of drug abuse of the child.

\section{Conclusion}

The efforts of the Government in eliminating drug abuse in Nigeria at large has been severely constrained by factors such as, unemployment, idleness, peer group pressures, bad parental upbringing etc. The consequences of drug abuse have been so appalling in the society and have wasted lives, caused various crimes, broken homes, caused accidents etc. However, this situation can take a turn for better if all the recommendations in this study are used and strictly applied by the government, the community leaders, institutions authority and individual in our society.

\section{Recommendations}

Based on the findings from the study, the following recommendations were made:

1. Government should establish law enforcement for the inspection and persecution of firms and individuals caught in trafficking of drugs.

2. Government should organize educational programmes, media broadcasts, advertisement, seminars aimed at enlightening the students on the dangers and consequences of drug abuse.

3. Government should build a clinic/hospital for the treatment and rehabilitation of drug addicts as this will go a long way in the fight against drug abuse.

4. Government should establish skill acquisition centers in higher institutions and as this will help in keeping the students occupied.

5. Government should establish more companies and establishment so as to create job opportunities for the educated ones.

6. Parent should train their children in a good, cultured and godly way and send them to good schools, guard them jealousy from peer group pressure and influences, prevent them from associating with bad friends as this will help them cultivate a decent attitude and help them build confidence in themselves.

7. The National Agency for food and drug administration control (NAFDAC) should be empowered and encouraged to do their work effectively and accurately.

8. There should be an intense media campaign aimed at enlightening the students and indeed Nigerians as a whole on the dangers and consequences of drug abuse.

\section{Competing Interests Statement}

The researchers declare that there are no competing or potential conflicts of interest.

\section{References}

Alewu, B., \& Nosiri, C. (2014). Drug Abuse, Addiction and Dependence. https://doi.org/10.5772/58574

Andrew, C., \& Smith, G. (2003). Adolescent Drug Taking. New York: Pengaun Press Inc.

Balogun, S. K. (2006). Chronic intake of separate and combined alcohol and nicotine on body maintenance among albinorats. Journal of Human Ecology, 19(1), 21-24. https://doi.org/10.1080/09709274.2006.11905852

Bauman, K. E., Foshee, V. A., Ennett, S. T., Pemberton, M., Hicks, K. A., King, T. S., \& Koch, G. G. (2001). The influence of a family program on adolescent tobacco and alcohol. American Journal of Public Health, 91(4), 604-610. https://doi.org/10.2105/AJPH.91.4.604

Oshikoya, K. A., \& Alli, A. (2006). Perception of Drug Abuse amongst Nigerian Undergraduates. World Journal of Medical Sciences, 1(2), 133-139. https://doi.org/10.5923/j.phr.20160602.01

Fareo, D. O. (2012). Drug abuse among Nigerian adolescent's strategies for counselling. The Journal of International Social Research, 5(20), 341-347.

Fawa, M. S. (2003). Drug abuse eradication programme in schools: The relevance of team, approach alternative, in A. Garba (Ed.), Youth and drug abuse in Nigeria: Strategies for counselling, management and control. Kano: 
Matasa Press.

Gateway. (2015). Effects of drug abuse on health. Retrieved from https://www.gatewayfoundation.org/faqs/effects-of-drug-abuse/

Hawkins, J. D., Catalano, R. F., \& Miller, J. Y. (2002). Risk and protective factors for alcohol and other drug problems in adolescence and early adulthood: Implications for substance abuse prevention. Psychological Bulletin, 112, 64-105. https://doi.org/10.1037/0033-2909.112.1.64

Kamlesh, K. S., \& Soma, S. (2012). Substance abuse causes and consequences. Retrieved from https://www.researchgate.net/publication/246544796_Substance_Abuse_Causes_and_Consequences?

Kelly, R. (2008). Risk factors for methamphetamine use in youth: a systematic review. BioMed Central Pediatrics, pg. 8. https://doi.org/10.1186/1471-2431-8-48

Kindra, S., \& Brian, W. (2019). How Are Drugs Classified? Retrieved from https://luxury.rehabs.com/drug-abuse/classifications/

Kosterman, R., Hawkins, J. D., Haggerty, K. P., Spoth, R., \& Redmond, C. (2001). Preparing for the Drug Free Years: Session-specific effects of a universal parent-training intervention with rural families. Journal of Drug Education, 31(1), 47-68. https://doi.org/10.2190/3KP9-V42V-V38L-6G0Y

McCabe, S. E., Boyd, C. J., \& Teter, C. J. (2009). Subtypes of nonmedical prescription drug misuse. Drug Alcohol Depend, 102(1-3), 63-70. https://doi.org/10.1016/j.drugalcdep.2009.01.007

Michael, B. (July 02, 2019). Drug Classes Making Sense of Medication Classification. Retrieved from https://www.verywellhealth.com/drug-classes-1123991

Natasha, T. (April 23, 2019). Drug Abuse Causes: What is the Cause of Drug Abuse? Retrieved from https:/www.healthyplace.com/addictions/drug-addiction/drug-abuse-causes-what-is-the-cause-of-drug-abus e

National Council of Educational Research and Training. (NCERT, 2019). Causes and consequences of substance/ drug abuse Retrieved from: http://www.ncert.nic.in/about_ncert.html

National Drug and Alcohol Research Centre. (NDARC, 2017). A quick guide to drugs \& alcohol. Retrieved from: https://yourroom.health.nsw.gov.au/publicationdocuments/quick-guide-ed3.pdf

National Institute of Drug Abuse. (2003). Preventing drug use among children and adolescents: A research-base guide for parents, educators and community leaders. Retrieved from https://www.drugabuse.gov/sites/default/files/preventingdruguse_2.pdf

National Institute of Drug Abuse. (2014). Principles of Adolescent Substance Use Disorder Treatment: A Research-Based Guide. Retrieved from https://www.drugabuse.gov/publications/principles

National Institute of Drug Abuse. (2017). Health Consequences of Drug Misuse. Retrieved from https:/www.drugabuse.gov/related-topics/health-consequences-drug-misuse

Nnachi, R. O. (2007). Advanced psychology of learning and scientific enquirie. Enugu: J.J. Classic Publishers Ltd.

Okoye, N. N. (2001). The adolescents and hard drugs: A psychological concern in R. U. N., Okonkwo, \& R. O., Okoye (eds.), The Nigerian adolescent in perspective. A Publication of the Nigerian Society for Education.

Paddock, C. (2018). Cannabis and the brain: Recent studies shed new light. Retrieved from https://www.medicalnewstoday.com/articles/323673

Spoth, R. L., Redmond, D., Trudeau, L., \& Shin, C. (2002b). Longitudinal substance initiation outcomes for a universal preventive intervention combining family and school programs. Psychology of Addictive Behaviors, 16(2), 129-134. https://doi.org/10.1037/0893-164X.16.2.129

Substance Abuse and Mental Health Services Administration. (2017). Focus On Prevention Strategies and Programs to Prevent Substance Use. Retrieved from: https://store.samhsa.gov/system/files/sma10-4120.pdf

Vivek, B., \& Tharu, R. (2011). Psychoactive Substances/ Substance Abuse/Drug Abuse. Retrieved from http://www.medindia.net/patients/patientinfo/DrugAbuse_Causes.htm.

Webster-Stratton, C., Reid, J., \& Hammond, M. (2001). Preventing conduct problems, promoting social competence: A parent and teacher training partnership in Head Start. Journal of Clinical Child Psychology, 30(3), 282-302. https://doi.org/10.1207/S15374424JCCP3003_2

Wolfgang, E. N. (1973). Addiction and Consequences. Philadelphia: Aldine Publishers. 
World Health Organization. (2011). Substance abuse. Retrieved from http://www.who.int/topics/substance_abuse/en

\section{Copyrights}

Copyright for this article is retained by the author(s), with first publication rights granted to the journal.

This is an open-access article distributed under the terms and conditions of the Creative Commons Attribution license (http://creativecommons.org/licenses/by/4.0/). 